\title{
CLAUSTRA. PROPUESTA METODOLÓGICA PARA EL ESTUDIO TERRITORIAL DEL MONACATO FEMENINO ${ }^{1}$
}

\author{
CLAUSTRA. A METHODOLOGICAL PROPOSAL FOR THE \\ TERRITORIAL STUDY OF FEMALE MONASTICISM
}

\author{
Blanca Garí, Maria Soler Sala, Marta Sancho Planas, \\ DELFI-I. NIETO-ISABEL, ARACELI ROSILlO LUQUE \\ Universitat de Barcelona
}

\begin{abstract}
Resumen: Partiendo del concepto holístico de paisaje, este artículo es una aproximación metodológica a las potencialidades ofrecidas por la catalogación, cartografía y geoposicionamiento de los espacios de espiritualidad femenina de los Reinos Peninsulares para el estudio de los mismos de una forma integrada y sexuada al mismo tiempo. Ya sea mediante bases de datos relacionales o bien mediante los Sistemas de Información Geográfica (SIG), se busca una representación sobre el territorio de la distribución de los espacios de espiritualidad conocidos a través de las fuentes. Las cartografías históricas resultantes de este proceso, relacionadas aquí con el caso de estudio de Cataluña, se convertirán no sólo en una fuente elaborada para conocer la distribución de los centros monásticos de cada orden, sino también en una herramienta de conocimiento de las relaciones existentes tanto entre centros, como entre éstos y el territorio inmediato o más lejano, así como en un dispositivo que abre nuevas preguntas, nuevas hipótesis y nuevos horizontes de análisis.
\end{abstract}

Palabras clave: espacio; paisaje; espiritualidad femenina; monacato; arqueología; territorio.

\begin{abstract}
On the basis of a holistic idea of landscape, this paper presents cataloguing, mapping and georeferencing as methodological tools for achieving a comprehensive and gendered study of the spaces of female spirituality in the kingdoms of the Iberian Peninsula. Our goal is to represent the territorial distribution of spiritual spaces documented in the sources through both relational databases and Geographical Information Systems (GIS). The resulting historical maps, related here to the Catalan case study, will became a source useful not only for discerning the distribution pattern of the monastic centres of each order but also a tool for understanding existing relationships between those centres and their immediate or distant environments, They also pose new questions and hypotheses and open new horizons of analysis.
\end{abstract}

Keywords: space; landscape; female spirituality; monasticism; archaeology; territory.

\section{${ }^{1}$ Abreviaturas utilizadas: ACA = Archivo de la Corona de Aragón.}

Esta investigación ha sido propiciada por el proyecto del MICINN HAR2011-25127 "Claustra. Atlas de espiritualidad femenina en los reinos peninsulares" y se enmarca en los estudios impulsados por CLAUSTRA (www ub.edu/claustra). 


\section{SUMARIO}

1. Situar en el espacio. Un planteamiento teórico.- 2. El Atlas CLAUSTRA. Una herramienta de investigación.- 3 . Estudio territorial del monacato femenino medieval.3.1. El paisaje como herramienta de conocimiento-- 3.2. La integración de fuentes: documentos, arqueología y territorio.- 3.3. El uso de los sistemas de gestión, georreferenciación y análisis de la información: SGIH y SIG.- 3.4. Hacia una interpretación multinivel: unidad, relación con el entorno y estudio territorial.- 3.4.1. Unidad: Arqueología para el estudio de los recintos monásticos.- 3.4.2. Relación con el entorno: el monasterio dentro de la ciudad.- 3.4.3. Análisis territorial del monacato femenino medieval.- 4. Un caso de estudio: Cataluña.- 5. Bibliografía citada.

\section{SiTUAR EN EL ESPACIO. UN PLANTEAMIENTO TEÓRICO}

Paisaje. Al tornar la mirada hacia el pasado se contemplan fragmentos de un paisaje. Hacemos historia cuando miramos y describimos uno a uno esos fragmentos, los ponemos en relación, reconstruimos e interpretamos. Todo se dibuja y difumina en el horizonte del pasado: ríos, mares y montañas, ciudades y campos, hombres y mujeres, actos, sentimientos o experiencias. A veces, casi siempre, nos fijamos sólo en una parte o incluso en algo muy concreto: una ciudad, un mercado, unos hombres que imparten justicia, unas mujeres que van a buscar agua, una monja que se inclina sobre un manuscrito, criaturas que nacen, viejos que mueren, hospitales de peregrinos, batallas ganadas o perdidas, iglesias que se construyen o destruyen, hornos de carbón que humean, caminos que se recorren. Miramos algo concreto e ignoramos lo demás para avanzar y saber acerca de un aspecto. Pero al final somos conscientes de que todo forma parte de un paisaje y que, si queremos penetrar en lo concreto, hemos de atender a cuanto le rodea, situarlo desde su tiempo en el espacio, ponerlo en relación, dejar que teja su red, que forme parte de la vida.

De un tal convencimiento nació hace años el proyecto que con el tiempo tomó el nombre de CLAUSTRA. El interrogante histórico que sustentó en sus orígenes este proyecto fue el del papel de las mujeres en los importantes y rápidos cambios de la espiritualidad en Europa a partir del siglo XII. Es indudable que desde esa fecha las transformaciones en la espiritualidad medieval se hicieron patentes de forma general y a través de manifestaciones muy diversas en todo el conjunto de la cristiandad latina y en todas las regiones de Occidente. En este proceso destacan algunos trazos comunes que se dibujan con bastante precisión. Uno de ellos es el peso cuantitativo y cualitativo de los espacios de religiosidad femenina entre los siglos XII y XVI, pues sabemos que la proliferación no sólo de monasterios sino más en general de nuevas formas y espacios de espiritualidad femenina modificó por completo el 
paisaje de la geografía sagrada de Occidente ${ }^{2}$. Para entender este cambio y seguirlo en sus dinámicas de fondo creemos que es necesario un nuevo y doble acercamiento: por un lado, el monacato femenino debe sin duda insertarse en las transformaciones de conjunto, pero por otro es no menos necesario sexuar esa aproximación. Solo así, otorgando a la espiritualidad femenina un lugar específico en el paisaje general, no como simple variante de los estándares masculinos sino difiriendo de ellos en sus objetivos, en su función y en sus formas, podremos comprender los desarrollos complementarios de ambos en el conjunto de un paisaje global. Bajo esa nueva lente aparecen entonces nuevas preguntas y nuevas vías de investigación ${ }^{3}$.

Ese es el punto de partida del Atlas de espiritualidad femenina de los reinos peninsulares que, sin embargo, se asienta en un planteamiento metodológico extensible, creemos, a otros aspectos y problemáticas del paisaje medieval ${ }^{4}$.

\section{El ATLAS CLAUSTRA. UNA HERRAMIENTA DE INVESTIGACIÓN}

El Atlas CLAUSTRA es una plataforma activa, destinada a la comunidad científica y accesible a través de internet que cataloga y cartografía espacios de espiritualidad femenina medievales. Su principal objetivo es construir un conocimiento sistematizado, visual, interdisciplinar e interrelacionado del origen, desarrollo y transformación de estos espacios ${ }^{5}$. La plataforma se

\footnotetext{
2 Ya en los años noventa planteaban estas cuestiones investigaciones como las de A. Benvenuti, "In castro poenitentiae"; véase también más recientemente $\mathrm{M}^{\mathrm{a}} \mathrm{M}$. Graña, Religiosas y ciudades.

${ }^{3}$ Es la perspectiva adoptada desde la arqueología por T. Collins, The Other Monasticism. En torno al estudio del "paisaje monástico" femenino véase tambien J. Bond, Monastic Landscapes.

${ }^{4}$ La herramienta que será descrita a continuación (www.ub.edu/claustra) es obviamente aplicable, sea al conjunto del fenómeno monástico (masculino y femenino) de los reinos peninsulares como a otros aspectos de la investigación; de hecho se ha comenzado a trabajar sobre una posible colaboración con otros grupos de investigación para su aplicación a la topografía hospitalaria. Un primer resultado fue la comunicación (inédita) presentada por B. Garí y D-I. Nieto-Isabel, Topografía de la asistencia.

5 El planteamiento general de este proyecto coincide con algunos aspectos importantes del trabajo de otros grupos de investigación internacionales que están enfocados en líneas relacionadas con la elaboración de topografías o investigaciones sobre espacios monásticos y su difusión en red. Un precedente de topografía monástica en formato CD es: A. Benvenuti, C. Carpini, E. Degl'Innocenti, L. Tromboni, Topografia sacra della Toscana. Ejemplos de plataformas digitales destinadas sobre todo a la sistematización de documentación o entidades monásticas en forma de catálogo: Monastic Wales, http://www.monasticwales.org/, dirigido por Karen Stöber y Janet Burton; Monastic Matrix proyecto de espacio interactivo de religiosidad femenina dirigido por las profesoras Lisa Bitel y Marie Kelleher: http://monasticmatrix.usc. edu/ o Monasterium. Das virtuelle Urkundearchiv Europas, coordinado por el Institut zur Er-
} 
organiza a través de atlas y catálogos, el primero de los cuales es el Atlas de espiritualidad femenina los reinos peninsulares.

El Atlas está compuesto por mapas engarzados en una barra cronológica entre 1100 y 1545, con una periodicidad de 25 años. En ellos se muestra el origen y evolución (cambios de asentamiento, cambios de orden, etc.) de los diversos espacios de religiosidad femenina de la Edad Media peninsular: desde la existencia de núcleos de reclusas, beguinas, terciarias independientes o de vida comunitaria, a las órdenes monásticas medievales o las fundadas en el paso de la Edad Media a la Moderna, cerrándose, de momento, en el comienzo del Concilio de Trento (1545). Las entidades religiosas que van apareciendo en el mapa permiten acceder a las fichas correspondientes del catálogo.

El hecho de que los datos proporcionados por la investigación y recogidos en el catálogo puedan ser posicionados y, por tanto, visualizados directamente sobre el mapa, base de todo estudio topográfico, genera una base de datos que permite elaborar hipótesis sobre las corrientes espirituales y sus influencias mutuas, así como establecer patrones evolutivos que puedan ser contrastados por investigaciones posteriores.

Uno de los primeros resultados de CLAUSTRA es, de hecho, el conjunto de mapas históricos de los reinos peninsulares que sirven de base al propio atlas. La posibilidad de contar con una representación cartográfica históricamente fiable y en formato digital que abarque un contexto espaciotemporal tan amplio facilita el desarrollo de todo tipo de estudios centrados en ese mismo marco ${ }^{6}$.

Junto al Atlas propiamente dicho el Catálogo, formado por las fichas descriptivas de los diversos espacios de espiritualidad femenina, ofrece un estado de la cuestión de lo que hoy sabemos sobre cada una de las comunidades, con enlaces a los correspondientes estudios, tesis, archivos, bibliotecas etc. El catálogo permite criterios diversos de búsqueda y a su vez da acceso a los mapas del Atlas.

Tanto el Catálogo como el Atlas aportan además, como elemento específico y diferencial, una reconceptualización de la noción de "espacios de espiritualidad" que es en sí misma una propuesta de renovación de las investigaciones sobre el tema. De una forma amplia y flexible y más allá de las entidades monásticas o conventuales concretas, CLAUSTRA incluye en su sistematización y análisis todos los testimonios de actividad espiritual que

schließung und Erforschung kirchlicher Quellen, St. Pölten/Austria: http://www.monasterium. net/.

${ }^{6}$ Los mapas históricos que sirven de base cartográfica del proyecto CLAUSTRA, elaborados por Carlos López-Arenillas y Delfi-Isabel Nieto-Isabel, serán publicados como resultado independiente en un artículo actualmente en preparación.

ANUARIO DE Estudios Medievales, 44/1, enero-junio 2014, pp. 21-50

ISSN 0066-5061, doi:10.3989/aem.2014.44.1.01 
formal o informalmente puedan situarse en el espacio y el tiempo, proporcionando así una información potenciadora de nuevas hipótesis y estudios para la comunidad científica.

La base de datos relacional que constituye el núcleo del Catálogo, está diseñada conforme a una jerarquía de categorías que permiten aprovechar al máximo la flexibilidad de nuestro concepto de espacio, posibilitando asî tanto una visión panorámica como una visión detallada de la realidad que pretendemos comprender.

La georreferenciación de la información contenida en el catálogo posibilita, no sólo las distintas funcionalidades del Atlas sino también el posterior desarrollo de contenidos mediante la utilización de metodologías novedosas como la que proponemos en los siguientes apartados de este artículo.

\section{ESTUDIO TERRITORIAL DEL MONACATO FEMENINO MEDIEVAL}

En este sentido, una vez realizada la recopilación de casos y el posicionamiento de los mismos en el Atlas, éste se convierte en una fuente elaborada de gran calado para el estudio territorial del monacato femenino medieval. Las Tecnologías de la Información y la Comunicación [TIC] nos ayudan a ello: ya sea mediante bases de datos relacionales a partir de las cuales almacenar ese geoposicionamiento y esa información acerca de los distintos centros monacales estudiados; o bien mediante los Sistemas de Información Geográfica (SIG), que nos permitirán representar sobre el territorio la distribución de los espacios de espiritualidad conocidos a través de las fuentes. Las cartografías históricas resultantes de este proceso se convertirán no sólo en una fuente elaborada para conocer la distribución de los centros monásticos de cada orden, sino también en una herramienta de conocimiento de las relaciones existentes tanto entre centros como entre éstos y el territorio inmediato o más lejano del que jamás han sido extraños. Para ello debemos integrar el estudio territorial en el concepto holístico de paisaje.

\subsection{El paisaje como herramienta de conocimiento}

La propuesta metodológica que aquí presentamos se basa en la consideración de que, como afirmábamos antes, la espiritualidad femenina, al igual que cualquier otra faceta económica, política, social o cultural de una determinada sociedad, forma parte de una realidad histórica compleja que puede ser entendida como paisaje, es decir, como espacio de interactuación entre todos los sistemas de relaciones que constituyen la realidad. Se trata de un 
concepto de paisaje heredero de las consideraciones apuntadas por el polímata Alexander von Humboldt a mediados del siglo XIX ${ }^{7}$, ampliamente utilizado por la Geografía y con menor intensidad por los estudios históricos ${ }^{8}$, donde destacan las precursoras aportaciones realizadas por la escuela de los Anales a mediados del siglo $\mathrm{XX}^{9}$, o a nivel arqueológico, los estudios procedentes de la Landscape Archaeology ${ }^{10}$ en los años sesenta y por la New Archaeology ${ }^{11}$ durante la década de los setenta. A partir de los años ochenta, destaca la abundante producción científica desarrollada por el Centre d'Histoire Ancienne de la Universidad de Besançon ${ }^{12}$ y, más recientemente, por el proyecto Archeologia dei Paesaggi Medievali de la Universidad de Siena, que mediante el Laboratorio di Informatica Applicata all'Archeologia Medievale (LIAMM) se ha convertido en punto de referencia en el estudio del paisaje a nivel europeo. Aunque con un considerable retraso, el concepto de paisaje también ha sido utilizado por los investigadores peninsulares. Cabe destacar aquí los seminarios de arqueología espacial organizados por el Colegio Universitario de Teruel desde los años ochenta ${ }^{13}$, o la investigación desarrollada por el Grupo de Investigación en Arqueología y Paisaje de la Universidad de Santiago de Compostela ${ }^{14}$.

En Cataluña, la producción de estudios relacionados con esta materia ha sido también importante. Con relación a la época medieval cabe destacar la abundante producción científica desarrollada desde la Universitat de Lleida

7 En los años centrales del siglo XIX, Alexander von Humboldt insistió en la importancia de las interrelaciones que se establecen entre los elementos que constituyen el paisaje. Lo hizo en su extraordinaria obra Kosmos. Entwurf einer physischen Weltbeschreibung publicada entre 1845 y 1858

${ }^{8}$ Sobre la evolución del concepto de paisaje en la Geografía y su progresiva aplicación en los estudios históricos y arqueológicos, véase A. Mauri, La configuració del paisatge, pp. 9-14 a quien hemos seguido en esta breve síntesis conceptual.

${ }^{9}$ Especialmente Marc Bloch, quién mostró un interés especial por el aspecto y sectorialización social y económica del territorio en obras como Les caractères, o su ya clásica La société féodale. Al igual que Lucien Fevbre, entienden la Historia como un todo: una historia total capaz de tener en cuenta los múltiples aspectos de la actividad humana.

10 J.S.P Bradford, Ancient Landscape, obra que consagró el interés del paisaje como fuente histórica. Sobre la incorporación del concepto paisaje en el campo de la arqueología véase A. Orejas, Arqueología del paisaje, pp. 191-230.

${ }^{11}$ Destacan aquí los precursores estudios de D.L. Clarke (ed.), Spatial Archaeology; I. Hodder, C. Orton, Spatial Analysis in Archaeology; o los trabajos de G. Bertrand, L'Archéologie du paysage, pp. 132-138. Este trabajo está considerado como uno de los precursores de la ecología histórica.

12 G. Chouquer, Cours d'Archéomorphologie, Carto-interprétation, Photo-interprétation; G. Chouquer, Quels scénarios; G. Chouquer, Traité d'archéogégraphie.

${ }_{13}$ Es mención obligada la producción ininterrumpida de estudios y análisis sobre arqueología del paisaje en los volúmenes de la revista Arqueología Espacial, publicada desde el año 1984.

${ }^{14}$ F. Criado, Del terreno al espacio. 
por Jordi Bolòs ${ }^{15}$, o los novedosos e interdisciplinarios análisis territoriales de Josep Maria Palet ${ }^{16}$ sobre la evolución del paisaje catalán. Siguiendo esta línea de análisis, y haciendo gala de una extraordinaria madurez conceptual, disponemos de la tesis doctoral de Alfred Mauri ${ }^{17}$, quien asienta de manera definitiva las bases metodológicas del estudio del paisaje medieval. A tenor de los resultados obtenidos a lo largo de estos últimos años ${ }^{18}$, creemos que esta forma de trabajo tiene validez suficiente para ser utilizada no sólo en un marco de estudio estrictamente territorial (como habitualmente ha sucedido hasta hoy), sino que se puede aplicar también a otros ámbitos económicos, políticos o culturales de las sociedades del pasado. Así lo hemos visto en el estudio de los mercados feudales realizado por una de las autoras del presente artículo $^{19}$, y así creemos que puede ser de gran interés también en el análisis del monacato femenino medieval.

Nuestro trabajo se basa en una concepción de la realidad histórica entendida como un sistema integrado, capaz de incluir cualquier aspecto del pasado dentro de un sistema de análisis global concebido como paisaje $e^{20}$. Cuando hablamos de paisaje, y más concretamente de paisaje histórico, nos estamos refiriendo a algo más que a territorio o paleoambiente, que a cartografía histórica o geografía regresiva. Nos referimos en realidad -o al menos así pretendemos hacerlo- a la globalidad del pasado. Porque todo forma parte del pasado. Tanto un bosque de robles documentado en el término del Castro Episcopale medieval ${ }^{21}$, como la referencia al río Llobregat aparecida en los pergaminos de la Cancillería ${ }^{22}$, como también la presencia de una comunidad

15 J. Bolòs, Els orígens medievals. Cabe destacar aquí, bajo la edición de este mismo autor y del profesor Joan J. Busqueta, la publicación de los cinco volúmenes de Territori i societat a l'Edat Mitjana: història, arqueologia, documentació, hoy bajo el título Territori i societat: el paisatge històric, que constituyen uno de los mejores exponentes de la actualidad investigadora sobre la historia del paisaje medieval en Cataluña.

16 J.M ${ }^{a}$ Palet, Estudi territorial del Pla de Barcelona. Cabe destacar también otros estudios: J. Palet et al., Formes d'ocupació, pp. 229-253; J. Palet et al., Formas de paisaje, pp. 67-79; H. Orengo, Arqueología de un paisaje. El análisis multi-proxy que estos autores aplican en sus estudios supone la integración de múltiples datos de carácter paleoambiental tales como analíticas palinológicas, paleocarpológicas, edafológicas sin olvidar los datos procedentes de la investigación arqueológica y documental.

17 A. Mauri, La configuració del paisatge.

18 A. Mauri, M. Soler, Les conques baixes del Llobregat i l'Anoia, pp. 209-225; A. Mauri, M. Soler, M. Vives, Paisatge i mercat; J.C. Guix et al., Introducción y colonización, pp. 125165; A. Mauri, M. Soler, Els castells, pp. 131-140.

${ }_{19}$ Véase M. Soler, Els espais d'intercanvi.

${ }^{20}$ Esta concepción aparecía ya en los estudios de María de Bolós, quién entendía el paisaje como una "concepción holística de la realidad integrada". M. de Bolós, Cuestiones de terminología, p. 71.

${ }^{21}$ ACA, Cancillería, pergaminos, número 445, año 1050. Documento inédito.

22 ACA, Cancillería, pergaminos, carpeta 109, doc. 79, año 1278. Documento inédito. 
de deodatas conocida documental y arqueológicamente en el Turó de la Capella de Castellbisbal ${ }^{23}$. Los tres elementos forman parte del paisaje y mantienen una intensa relación entre ellos, aunque cada uno pertenezca a un ámbito diferenciado: el bosque al subsistema biótico, el río Llobregat al subsistema abiótico y la comunidad religiosa al subsistema antrópico. Todos ellos, y sus respectivas interactuaciones (abundantes por la cercanía de ésta última a ambas fuentes de recursos naturales), forman parte de la realidad histórica y deben poder ser analizadas conjuntamente.

Entendido de esta forma, el paisaje constituye un poderoso método de análisis del pasado. Una manera de superar la secuencialidad del discurso histórico -necesariamente lineal-, para pasar a una concepción hipertextual de la Historia, en la que los hechos no son nunca sólo diacrónicos, sino que también pueden suceder de manera sincrónica y relacionarse entre ellos. El paisaje nos ofrece así una valiosa puerta de acceso a la complejidad ${ }^{24}$.

\subsection{La integración de fuentes: documentos, arqueología y territorio}

La apuesta por el estudio global del pasado nos obliga a analizar de manera integrada todo tipo de fuentes: documentales, arqueológicas y territoriales para poder estudiar no solamente cada uno de los centros monásticos en sí mismos, sino también la relación que se establece entre ellos y su entorno inmediato o más lejano. Para ello debemos hacer uso de las fuentes documentales inéditas o publicadas que tenemos a nuestra disposición, impulsando el estudio de las mismas y potenciando la investigación de fondos en los archivos custodiados por distintas comunidades religiosas todavía hoy en activo, así como el seguimiento de archivos dispersos o desplazados, fondos de bibliotecas antiguas, patrimonio arquitectónico y artístico, etc. Pero no basta. Es también necesario el acceso a la información procedente de la arqueología y del territorio.

En aquellos casos en que se disponga de restos materiales del centro espiritual en cuestión o de algunos de los elementos que lo integran, la arqueo-

\footnotetext{
${ }^{23}$ Poca información disponemos sobre la presencia de deodatas en el Turó de la Capella de Castellbisbal (Vallès Occidental) en la Edad Media, más allá de las referencias publicadas por A. Ruiz, Notes històriques, quién las documenta por primera vez en 1216 hasta que se integran en la comunidad de monjas agustinianas de Montalegre. También disponemos de los datos procedentes de la prospección geoeléctrica realizada por el geólogo Narcís Carulla y el arqueológo Alfred Mauri en el año 2001: A. Mauri, N. Carulla, La casa de Deodades, pp. 129-132.

24 A. Mauri, La configuració del paisatge, p. 14. También, M.P. Guermandi, La Sfida, pp. 441-445.
} 
logía nos puede ser de gran ayuda, especialmente a través de las memorias de excavación inéditas o publicadas de aquellos espacios monásticos donde se haya realizado intervenciones arqueológicas. Éstas nos ofrecerán conocimiento sobre la distribución y usos de los distintos ámbitos que forman parte del monasterio.

El interés por relacionar los espacios monásticos con su entorno (ya sea en el ámbito de una ciudad, en el entorno rural inmediato o en el marco de un territorio más amplio) nos obliga a hacer uso también de las fuentes territoriales. Nuestro acercamiento a las mismas debe realizarse a partir de una doble perspectiva. En primer lugar, y desde un punto de vista amplio, el territorio nos interesa por la información que es capaz de aportar sobre las formas de ocupación y explotación del medio. En este sentido, por ejemplo, la presencia de agua abundante o la existencia de suelos fértiles en un espacio determinado favorecerá el asentamiento de comunidades humanas que encontrarán en dichas condiciones el incentivo suficiente para instalarse. Siguiendo con el mismo ejemplo anterior, es posible que la comunidad de deodatas de Castellbisbal valorara la abundante presencia de agua en este territorio como elemento fundamental para su asentamiento. El conocimiento de las características geológicas y edafológicas del territorio nos ayudan a conocer los condicionantes territoriales sobre los que se asienta la actividad humana. Tenga ésta un carácter económico o espiritual.

En segundo lugar, y desde un punto de vista más restringido, nuestro interés por el territorio se encamina también hacia el estudio del parcelario urbano actual, en el que se asentaron numerosos centros de espiritualidad femenina. El trazado antiguo de los núcleos de población actuales, así como la disposición de algunos elementos que se han conservado en ellos desde época medieval (iglesias, plazas de mercado, palacios, torres), convierten a la trama urbana en una fuente de gran valor para conocer su morfología original $^{25}$. La toponimia de calles y plazas, los hagiónimos de las iglesias o la denominación popular de algunos espacios, en muchos casos continúan siendo muy interesantes para conocer la sectorialización de la ciudad medieval. El estudio territorial deberá contar con tres fuentes fundamentales: la cartografía actual, la cartografía histórica y la prospección directa del territorio.

${ }^{25}$ B. Arízaga, La recuperación del paisaje, p. 31. 


\subsection{El uso de los sistemas de gestión, georreferenciación y análi- sis de la información: SGIH y SIG}

A partir de estos planteamientos previos, todas y cada una de las informaciones localizadas en las fuentes han de introducirse en un sistema de bases de datos relacional, de modo que en él los datos de cada uno de los centros monásticos (que constituyen la base del Atlas CLAUSTRA) queden almacenados junto con todo tipo de información procedente de cualquiera de las fuentes históricas disponibles en una misma base de datos, convertida así en un verdadero Sistema de Gestión de la Información Histórica $(\mathrm{SGIH})^{26}$ capaz de gestionar de manera integrada información de origen y procedencia diferente. En esta base de datos, los campos informativos, de datación cronológica y de ubicación concreta (coordenadas X e Y) o relativa (en función de un ámbito territorial conocido) serán fundamentales para el trabajo posterior.

Una vez cumplimentadas las fichas, la información registrada será traspasada a los Sistemas de Información Geográfica [SIG]. El SIG es una aplicación informática que nos permite tanto acceder a los atributos de los objetos espaciales a partir de su representación cartográfica, como cartografiar de manera automática los objetos espaciales en función de sus atributos. El SIG incluye funciones de una base de datos relacional y herramientas propias de la cartografía asistida por ordenador y, en mayor o menor medida, de análisis espacial. Todo ello convierte a los SIG en una herramienta adecuada tanto para el registro de la información como para la representación gráfica y cartográfica, así como también para la gestión y el análisis de la información ${ }^{27}$. El uso de los SIG nos permitirá así introducir la coordenada espacial en nuestro estudio, dado que nos ofrecerá la posibilidad de representar toda la información recogida sobre el territorio. La situación de cada unidad informativa sobre el mapa se realizará a partir del campo de ubicación territorial incluido en la base de datos, el cual nos ofrecerá la posibilidad de geoposicionar automáticamente cada dato en su ubicación geográfica específica.

El trabajo por capas nos permitirá representar sobre el territorio toda la información almacenada, independientemente del carácter y del origen de la fuente. Estas capas informativas las superpondremos a una cartografía base

${ }^{26}$ Adoptamos aquí la denominación que le da Alfred Mauri en su trabajo y que también fue adoptada por María Soler en su tesis doctoral: A. Mauri, La configuració del paisatge; M. Soler, Els espais d'intercanvi.

27 Sobre el interés de los SIG en los estudios históricos, véase: J.F. Berger, F. Bertoncello, F. Braemer, G. Davtian, M. Gazenbeek (dirs.), Temps et espaces; A. Kelly, A. Hillier (eds.), Placing History; D.J. Bodenhamer, J. Corrigan, T.M. Harris (eds.), The Spatial Humanities. 
formada por los límites administrativos actuales o históricos, el mapa hidrográfico general y un mapa base topográfico.

Así pues, para un estudio como el que proponemos, los SIG nos proporcionan algo más que una simple herramienta de ilustración cartográfica. En primer lugar, nos permiten una representación rápida y eficaz de la información histórica sobre el mapa, ya que el geoposicionamento de objetos es el resultado de un proceso de georreferenciación prácticamente automático. Por otro lado, los SIG nos ofrecen también utilidades de base de datos relacional, de gran interés a la hora de realizar búsquedas y mapas temáticos a partir de la información introducida. En tercer lugar, el amplio abanico de prestaciones analíticas y de cálculo estadístico que incorporan nos será de gran utilidad en la fase interpretativa de nuestro estudio dado que nos permitirá cuantificar algunos de los fenómenos estudiados.

Todo ello determina que el resultado de la elaboración de los datos, es decir, la planimetría histórica surgida de este proceso analítico, no sea una simple ilustración de lo que se pretende explicar sino una fuente elaborada a partir de la cual asentaremos nuestra interpretación histórica.

\subsection{Hacia una interpretación multinivel: unidad, relación con el entorno y estudio territorial}

La aplicación del SIG a los estudios históricos hace desaparecer la preocupación por la escala geográfica y nos ofrece la oportunidad de trabajar desde cualquier tipo de aproximación territorial. La especificidad de nuestra investigación a menudo nos obligará a trabajar a escalas mayores (1:25.000 o superiores), por ejemplo cuando analicemos la distribución de los centros monacales en relación a los espacios productivos o a la articulación de la red viaria. Pero también tendremos que trabajar a escalas más pequeñas (1:5.000 o inferiores), especialmente para analizar el centro monástico concreto o su relación con el espacio circundante más inmediato. De este modo la unidad, la relación con el entorno y el análisis territorial se presentan como tres niveles claramente complementarios.

\subsubsection{Unidad: arqueología para el estudio de los recintos monásticos}

Es evidente que, además de las fuentes documentales más habitualmente presentes en los estudios del monacato en general y del monacato femenino en particular, la arqueología de los espacios femeninos de espiritualidad, integrada en la arqueología del monacato peninsular, ha de ser uno de los elementos imprescindibles de nuestra investigación. 
En los entornos rurales de la Península Ibérica, la implantación de comunidades monásticas se remonta al período de transición entre la tardoantigüedad y la Alta Edad Media. Las reglas monásticas previas a la implantación de la norma benedictina son diversas y conocidas, así como las referencias a monasterios que encontramos en las actas de los concilios desde el siglo VI.

A pesar de disponer de estas noticias, su conocimiento desde el punto de vista arqueológico es muy limitado. Algunas aportaciones proponen el carácter monástico de iglesias como la de Santa María de Melque así como de otras iglesias de planta cruciforme como la de Santa Comba de Bande, y ha abierto el debate sobre la interpretación de estas iglesias poniendo en duda la relación directa entre la tipología de planta y su función monástica ${ }^{28}$.

Probablemente la mayoría de estos primitivos monasterios tienen su origen en comunidades eremíticas que progresivamente se van dotando de espacios comunitarios de culto y convivencia, lo que impone la redacción de reglas adecuadas para la gestión y uso de dichos espacios. Este sería el caso arqueológicamente documentado del monasterio de Sant Llorenç prop Bagà ${ }^{29}$ y del más antiguo de la península documentado por escrito de Sant Martín de Asán ${ }^{30}$.

La estructura y organización espacial de estos primitivos monasterios nada tiene que ver con el modelo claustral impuesto a partir del siglo IX como consecuencia de las reformas impulsadas por los carolingios.

En el área catalana disponemos de algunas evidencias arqueológicas correspondientes a estos primitivos monasterios. Es el caso de Sant Llorenç de Sous, Sant Pere de Rodes, Sant Llorenç prop Bagà y Sant Cugat del Vallès. Generalmente se trata de muros y estructuras muy arrasadas, localizadas bajo las edificaciones correspondientes a los niveles de los siglos X y XI relacionadas con las reformas introducidas alrededor del año 1000. En la mayoría de casos se ha podido constatar la existencia de una iglesia y de edificaciones anejas que corresponderían a espacios propios de la comunidad sin que sea posible definir su función concreta. Las recientes excavaciones, aún en curso, en el yacimiento de Els Atimiris, están sacando a la luz un complejo formado por iglesia y dependencias anejas que se interpreta como uno de estos primitivos monasterios fechados entre los siglos VI-IX ${ }^{31}$.

\footnotetext{
${ }^{28}$ L. Caballero, El conjunto monástico; J.A. García, R. Teja (coords.), Monjes y monasterios hispanos, pp. 99-146. También, L. Caballero, F. Arce, M.A. Utrero, Santa Comba de Bande, pp. 69-73.

29 J. Bolòs, Monestir de Sant Llorenç prop Bagà, pp. 11-12. También, A. López, A. Caixal, J.M. Vila, El monestir de Sant Llorenç, pp. 35-48.

${ }_{30}$ J. Fortacín, La donación del diácono, pp. 7-70.

${ }_{31}$ M. Sancho, Els Altimiris, pp. 67-90.
} 
A partir del siglo X y con más intensidad desde el siglo XI, se impondrá progresivamente el modelo claustral, caracterizado por la existencia de un claustro alrededor del cual se sitúan todas las dependencias que constituyen el monasterio, incluida la iglesia ${ }^{32}$.

Este modelo está sujeto a variaciones según las características del solar en el que se edifica y de las construcciones anteriores reaprovechadas y transformadas que quedarán integradas en el conjunto ${ }^{33}$.

Como es sabido, la articulación del espacio monástico a partir de un claustro se basa en el plano de la abadía ideal conservado en Saint Gallen, inspirado en las propuestas expuestas por la regla benedictina. En el caso de monasterios modestos, el modelo se limita a las estancias propias de la comunidad articuladas a través del claustro como espacio central, pero, en el caso de grandes abadías, el monasterio se extiende llegando a constituir un urbanismo complejo y ordenado con edificaciones vinculadas a actividades económicas y de asistencia y delimitadas por un perímetro amurallado. En Cataluña tenemos un magnífico ejemplo de este modelo para el monacato masculino en la abadía de Poblet. El estudio comparativo de este modelo con las formas desarrolladas por el monacato femenino, mucho menos estudiadas, ha de mostrar una vez más las semejanzas y las diferencias sujetas a las funciones y objetivos de uno y otro, especialmente marcadas por la práctica de la clausura y el papel de las mujeres en la espiritualidad de la Edad Media occidental ${ }^{34}$.

Así pues desde el punto de vista del análisis espacial, debemos tener en cuenta una serie de aspectos internos que condicionan la actividad y la vida dentro del monasterio:

- Las características y necesidades específicas de los monasterios femeninos y masculinos respectivamente con especial atención a la "espacialización" de la clausura femenina y sus formas de relación con el entorno.

- Mayor o menor grado de aislamiento respecto el exterior: existencia o no de un perímetro amurallado, espacios de acceso restringido y de espacios compartidos.

- Circulación interna: accesos, zonas de paso y de encuentro.

32 J.A. Adell, Arquitectura alt-medieval a Cataluña.

${ }^{33}$ De hecho CLAUSTRA, aunque no está cerrado a ulteriores ampliaciones, comienza por el momento a partir de esta fecha, atendiendo a su principal objetivo que es estudiar la gran expansión del monacato femenino a partir del siglo XI.

${ }_{34}$ Sobre la especifidad de espacios monásticos femeninos en la Corona de Aragón véase B. Garí, The Sacred Space. 
- Funcionalidad de los espacios: espacios de culto, de hábitat, de producción y trabajo, asistenciales.

- Presencia territorial más allá del recinto monástico: propiedades del monasterio que constituyen su patrimonio, derechos de uso de determinados recursos como aguas, fuentes o pastos, instalaciones de transformación de productos como molinos, hornos o lagares.

Estos aspectos inciden en las formas de vida cotidiana, en las interacciones que se producen entre los miembros de la comunidad y el exterior, en el desarrollo de rituales y ceremonias religiosas, en las formas de trabajo y en la misma economía del monasterio.

Por otro lado existen condicionantes externos que también influyen en las características de un monasterio como su ubicación en un entorno urbano, periurbano o rural, su situación respecto determinados elementos geográficos tales como ríos, mar, montañas o llanos, la climatología del lugar.

Finalmente podemos plantearnos, más allá de la especificidad del monacato femenino, si la pertenencia a una u otra orden o incluso a una u otra comunidad incide en las características físicas del conjunto monástico y en la definición de unos determinados espacios.

Todos estos condicionantes configuran una realidad distinta en cada monasterio de forma que es posible encontrar variantes del modelo claustral con distintas ubicaciones del claustro respecto la iglesia, con espacios destinados a múltiples funciones, con accesos desde el exterior muy diversos y con circuitos internos dispares.

El proyecto CLAUSTRA nos aporta para este tipo de análisis una cantidad suficiente de información sistematizada que podremos releer para intentar establecer y definir alguno o muchos de los aspectos aquí planteados.

\subsubsection{Relación con el entorno: el monasterio dentro de la ciudad}

Los centros monásticos establecidos dentro del espacio urbano mantienen una estrecha relación con la ciudad en la que se asientan, de manera que estudiar su entorno inmediato nos debe ayudar a conocer mejor también el monasterio en cuestión ${ }^{35}$. Así lo hemos visto en la ciudad de Barcelona, donde la intensa actividad arqueológica desarrollada en los últimos años nos permite

\footnotetext{
35 Sobre la relación entre centros monásticos y ciudad cabe destacar la publicación de varios trabajos en C. Caby et al., Espaces monastiques et espaces urbains. 
afianzar nuestro conocimiento sobre los monasterios en sí mismos y su relación con la ciudad ${ }^{36}$. Así, el geoposicionamiento de los espacios de religiosidad femenina sobre la trama urbana histórica nos ha de ayudar a comprender la intensa relación existente entre la implantación monástica y la transformación del espacio urbano: es el caso, por poner un ejemplo, del monasterio de benedictinas de Sant Pere de les Puel·les de Barcelona, que generó el barrio de la Vilanova de Sant Pere ${ }^{37}$ o el de las clarisas de Sant Antoni de la misma ciudad, que, construido a mediados del siglo XIII en los márgenes del llamado "quarter del mar", contribuiría rápidamente a la población y urbanización de la zona ${ }^{38}$.

La estrecha relación existente entre espacio monástico y ciudad nos empuja a plantear un estudio regresivo del territorio urbano, a partir de la cartografía actual e histórica, con todos los datos procedentes de las fuentes escritas y la arqueología. La metodología de trabajo utilizada para realizar este tipo de estudio sigue las directrices explicadas en los apartados anteriores, pero cuenta con algunas herramientas $\operatorname{propias}^{39}$. El estudio morfológico del parcelario urbano se desarrolla a partir de tres grandes fases de trabajo: observación planimétrica, análisis integrado y definición de la secuencia histórica.

En primer lugar, nos planteamos observar atentamente la distribución y orientación de calles y vías, manzanas de casas y parcelas urbanas con el objetivo de percibir las similitudes y diferencias existentes entre los distintos sectores que constituyen el parcelario urbano actual de un núcleo de población de origen medieval. Este proceso nos permitirá identificar como Unidades de Desarrollo [UD] a aquellos ámbitos urbanos dotados de una coherencia morfológica similar ${ }^{40}$.

El estudio integrado de la topografía urbana y de las fuentes históricas (documentales, arqueológicas y territoriales) nos permitirá dotar de una cronología relativa les diversas Unidades de Desarrollo [UD] detectadas en la primera fase del trabajo. La existencia de noticias materiales o escritas de una determinada cronología para una de les UD identificadas

36 E. Riu-Barrera, L'arqueologia dels monestirs, pp. 185-192.

37 E. Cantarell, M. Comas, Espais de religiositat femenina, p. 135. Aunque de una cronología algo posterior, resulta muy sugerente también el estudio de C. Busquets, I. Pastor, Una transformació de l'espai urbà, pp. 147-153.

38 N. Jornet, El monestir de Sant Antoni.

39 M. Soler, Estructura econòmica. Un resumen de los resultados obtenidos a través de este estudio se encuentra en M. Soler, Feudalisme i nucleació poblacional, pp. 69-101.

40 El concepto de Unidad de Desarrollo es muy similar a las Plan Units utilizadas por K. Lilley en el estudio evolutivo del núcleo urbano de Coventry (Inglaterra) durante los siglos XII y XIII. Mapping the medieval city, p. 13. Desde un punto de vista metodológico cabe destacar, más recientemente, G. Chouquer, L'analyse de morphologie urbaine. L'exemple de Beja (Portugal). 
no sólo nos permitirá conocer el momento de creación o consolidación de la misma, sino que también, por extensión, la cronología ante quem y post quem de las UD adyacentes. A la vez, el análisis integrado nos permitirá detectar cuáles han sido los elementos de polarización de un determinado núcleo urbano ${ }^{41}$. Dado que en muchos casos éstos tienen un carácter religioso (iglesia, monasterio, centro espiritual), este análisis puede resultar de gran interés a la hora de estudiar el impacto de estos espacios en la configuración del territorio urbano.

Después de analizar las diferentes UD y haberles asignado una cronología relativa estaremos en disposición de conocer la evolución del núcleo urbano en toda su extensión. Ordenaremos las distintas UD que la componen a través de una matrix secuencial, y representaremos las fases de desarrollo sobre una base cartográfica digital. El mapa resultante de este proceso, fruto de un trabajo reflexivo y hermenéutico, no debe tomarse como un resultado definitivo sino como un simple modelo teórico que tendremos que ir ajustando a medida que la investigación documental y arqueológica aporte nuevos resultados.

Teniendo en cuenta que las formas urbanas no son más que el resultado de una racionalización de la práctica del espacio ${ }^{42}$, el tejido urbano de cualquier núcleo o ciudad se nos representa como la adaptación a las necesidades humanas de quiénes conviven en ella; y su expansión o retraimiento será un indicativo de los cambios en las necesidades de espacio de sus habitantes. Una expansión urbana rápida y extensa entorno a un centro monástico concreto será testigo de su dinamismo económico y social, mientras que el inmovilismo y la retracción atestiguan su estancamiento o decadencia.

Finalmente, la forma urbana es también el espacio de proyección de las representaciones y jerarquías sociales imperantes. El análisis semiológico de las formas urbanas nos tendría que permitir entrar también en los sistemas de pensamiento de quiénes las crearon, en el estudio de la espiritualidad, la ideología, la voluntad y el imaginario colectivo de la sociedad de la que son testigo revelándonos, en este caso, el papel de las mujeres y de la espiritualidad femenina en ellas. Y es que, por decirlo en palabras de Gérard Chouquer, las formas urbanas no dejan de ser, al fin y al cabo, una verdadera memoria de las ideas ${ }^{43}$.

41 Estos polos de atracción son los "morfogenes" de los que habla G. Chouquer. Son los elementos a partir de los cuales se constituyen las formas. G. Chouquer, Cours d'Archéomorphologie, p. 47.

42 Ibidem, p. 4.

43 Ibidem, p. 47. 


\subsubsection{Análisis territorial del monacato femenino medieval}

Después del análisis individual y del análisis del entorno, llegamos al estudio de la globalidad, donde el marco ya no es el centro de espiritualidad concreto sino el conjunto de los mismos. Para hacerlo posible deberemos realizar varias cartografías históricas en las que posicionaremos todos los elementos estudiados. Empezaremos por los centros de espiritualidad conocidos en función de su cronología, determinando en cada caso si los estudiaremos todos o solamente los pertenecientes a una o más órdenes concretas, pudiendo además precisar la cronología o espacio territorial que queramos analizar.

Las herramientas SIG nos permitirán hacer un mapa sobre la progresiva implantación de monasterios en un área determinada. A partir de aquí decidiremos visualizar aquella información que nos interese, procedente de las distintas fuentes.

Pongamos, por ejemplo, que nos planteamos analizar la relación existente entre las comunidades monásticas femeninas y las vías pecuarias, aspecto de gran relevancia y que en los últimos años se está debatiendo en relación a todo el monacato tanto masculino como femenino, especialmente para los siglos altomedievales. El análisis SIG nos permitirá disponer de cartografía específica en la que se pongan en relación los monasterios con estas rutas de trashumancia y con las zonas de pasto. Podremos calcular distancias, alturas y rutas entre unos y otros elementos. lo mismo podemos hacer con las vías de comunicación, los pasos de montaña o los ríos. Y lo mismo sucederá con cualquier otro aspecto que nos propongamos estudiar y al que, disponiendo de información, podamos dar una dimensión territorial cartografiable.

Otro tipo de análisis a realizar se corresponde con el área de captación de recursos. Podemos establecer estas áreas calculando los desplazamientos a pie desde un centro que sería el propio monasterio, por un determinado tiempo (1 hora, 4 horas...), teniendo en cuenta además los desniveles del terreno que hay que superar. Una vez definida esta área, nos fijaremos en la características del terreno y en los tipos de recursos que se encuentran al alcance (agrícolas, ganaderos, forestales...). El mismo tipo de cálculo puede aplicarse a la existencia de mercados, a la frecuencia de monasterios femeninos o masculinos o a las concentraciones de hábitat.

Por último, en el marco de una reflexión sobre la globalidad, no pueden dejarse de lado las posibilidades que ofrecen los estudios de redes, entendidos éstos, más allá del planteamiento prosopográfico clásico, con toda la potencia que esta aproximación metodológica presta a las investigaciones 
históricas ${ }^{44}$. No se trata aquí de implementar nuevas herramientas de programario, sino más bien de utilizar la base de datos geoposicionada y su representación espacial SIG como una suerte de fuente secundaria que nos permita aplicar conceptos provenientes del análisis de redes para generar nuevas hipótesis de trabajo. Nociones como, por ejemplo, las medidas de centralidad e interconectividad pueden esclarecer y dibujar patrones de difusión y circulación, no sólo de libros u objetos devocionales, sino también de ideas, personas y corrientes espirituales; algo que precisamente se encuentra la línea de los objetivos centrales del proyecto CLAUSTRA ${ }^{45}$.

Así, esta "nueva cartografía”, cuyo propósito es mapear cómo emergen, qué forma cobran y cómo evolucionan las redes en las cuales se imbrican los espacios de espiritualidad femeninos, constituye una capa más de información que se suma a nuestros esfuerzos por dilucidar el paisaje medieval en su sentido más amplio.

Las herramientas SIG nos ofrecen para ello posibilidades múltiples y variadas. Su aplicación en nuestro proyecto estará sujeta a la propia evolución de la investigación y a los intereses concretos de cada una de las investigadoras implicadas. Por el momento hemos ensayado, a modo de ejemplo, la aplicación de las herramientas más inmediatas y directas a monasterios posicionados en la zona catalana, con la finalidad de valorar el potencial y los posibles resultados que de ellas podemos obtener.

\section{Un CASO DE ESTUdio: CATALUÑA}

A título de ejemplo, queremos plantear seguidamente el análisis de cuatro mapas que recogen información del Atlas CLAUSTRA referente a Cataluña. Los cuatro mapas muestran a diferentes niveles algunas de las potencialidades que ofrece el sistema de georreferenciación para plantear hipótesis y generar preguntas. La cartografía presentada superpone un mapa base orográfico, un mapa hidrográfico y un mapa de caminos.

44 A título ilustrativo de las posibilidades que ofrecen este tipo de estudios véanse, entre otros, B.H. Erickson, Social Networks pp. 149-157; J. Preiser, (Not so) Distant Mirrors.

${ }^{45}$ Para el uso de análisis de redes aplicados al estudio de fenómenos espirituales véanse, por ejemplo, A. Collar, Network Theory, pp. 149-162 y D-I. Nieto-Isabel, "Qui spiritus ambo sunt unum". 
Mapa 1: Beguinas y deodatas (1200-1450)

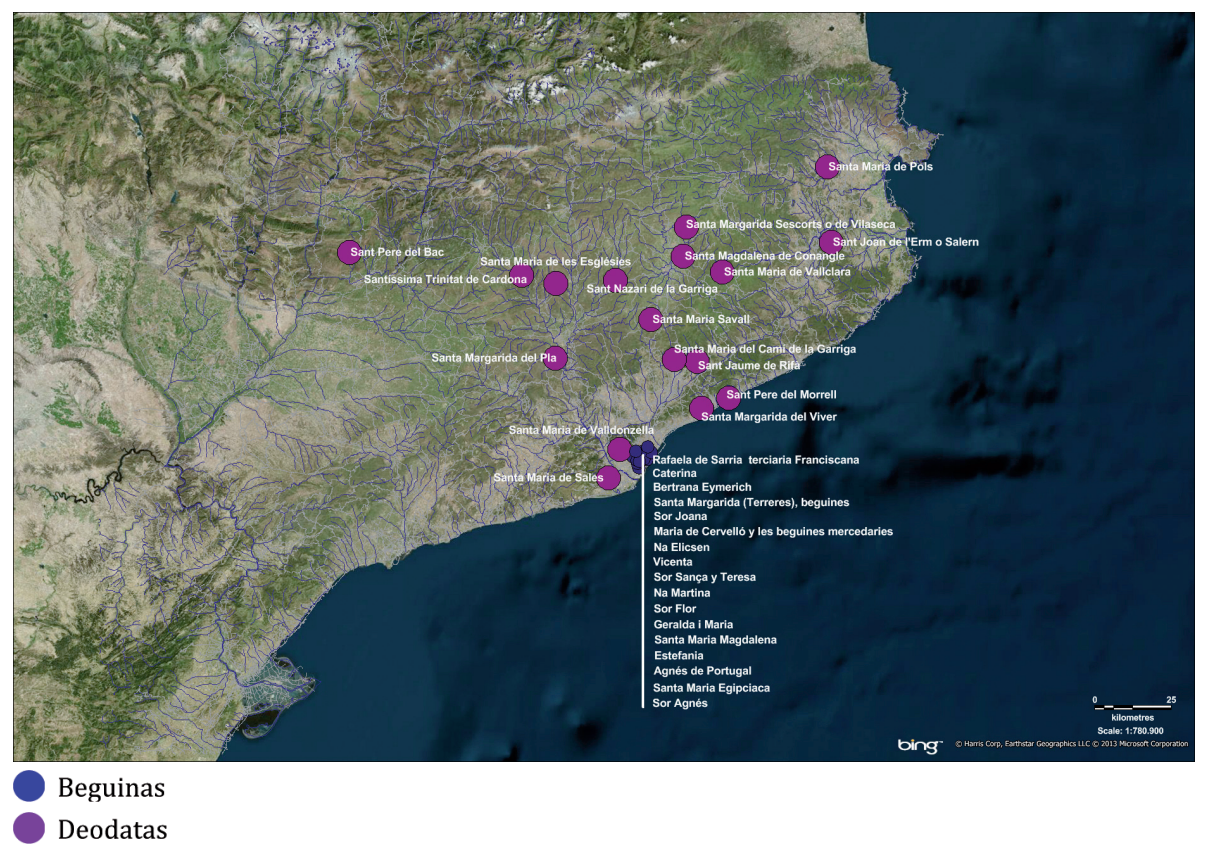

El primero de los cuatro mapas recoge las informaciones recopiladas hasta la actualidad sobre la presencia en Cataluña de beguinas y de comunidades de deodatas ${ }^{46}$. Antes de sacar ninguna conclusión debe advertirse el estado preliminar de este mapa que se presenta sobre todo como ejemplo de las posibilidades que esta metodología nos ofrece. Somos conscientes, sin embargo, de que aún hay mucho por hacer en la investigación sobre ambas realidades o formas de espiritualidad femenina, una investigación que CLAUSTRA pretende precisamente impulsar. Pero, en el estado actual de nuestros conocimientos, llama la atención hasta qué punto este primer mapa refleja y a la vez matiza algunos de los supuestos acerca de la deodatas y las beguinas, y acerca de la relación comparativa entre ambas. En primer lugar, el mapa confirma un fenómeno característico de los condados catalanes, esto es, la importancia de las comunidades de deodatas extendidas por todo el territorio, pero a la vez matiza la comprensión de estas comunidades como típicamente altomedievales. Desde 1200 y hasta al menos 1450 estas comunidades versátiles y flexibles en sus funciones, a menudo asistenciales, abundan en Cataluña.

\footnotetext{
46 M. Cabré, Deodicatae y Deovotae.
} 
Si se sigue en el Atlas la secuencia de 25 años de 1200 a 1450 se observan incluso escasas desapariciones y nuevas fundaciones. Sólo en la segunda mitad del siglo XV (ya fuera de este mapa) estas comunidades desaparecen con gran rapidez. En segundo lugar, el mapa deja ver la concentración urbana de beguinas individuales (no comunitarias) mencionadas en la documentación, todas ellas referenciadas en Barcelona, aunque tenemos alguna noticia también de Girona. Claramente, la principal diferencia entre estas dos formas de espiritualidad, ambas escasamente institucionalizadas, reside en su respectivo carácter rural y urbano.

Mapa 2: Comunidades femeninas clarisas y dominicas (1225-1500)

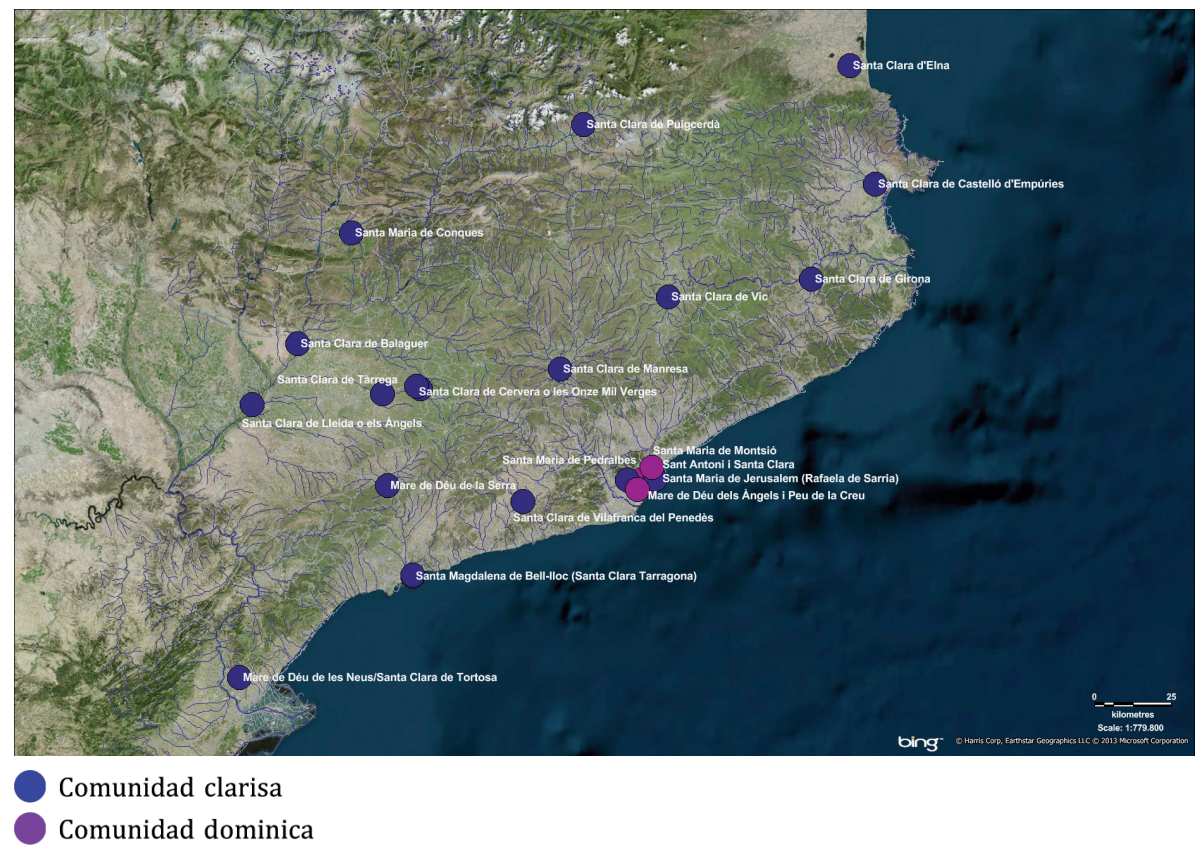

En el caso del segundo mapa llama la atención un fenómeno no por conocido falto de relevancia, es decir, el importante desequilibrio que se observa en la implantación de las principales órdenes femeninas mendicantes: clarisas y dominicas en Cataluña. El mapa, que presenta los monasterios de ambas órdenes entre 1225 y 1500, muestra la escasa presencia de las dominicas: se documentan sólo dos monasterios y ambos en la ciudad de Barcelona, el primero es de 1347 y el segundo se inicia en una fecha posterior a 1461 en Caldes de Montbui como comunidad de terciarias dominicas, posteriormente 
se traslada a Barcelona y sólo en 1497 se convierte en comunidad de la segunda orden. Ninguno de ambos monasterios tiene además durante la Edad Media la importancia y envergadura de algunos de los monasterios de clarisas. La razón de la práctica ausencia de dominicas en Cataluña es, al margen de algunas obviedades, todavía una incógnita a despejar en profundidad, más aun teniendo en cuenta la no desdeñable importancia de los Predicadores en la Corona de Aragón, especialmente en época trastámara. Por su parte, las fundaciones de monasterios de clarisas destacan cuantitativa y cualitativamente. El apoyo de las mujeres de la realeza y de las clases dirigentes urbanas a las clarisas es un tema que sigue estando sin duda en la primera línea de interés de la investigación. En relación al mapa, llama la atención su dispersión, ocupando con sus áreas de influencia una buena parte del territorio.

Mapa 3: Comunidades femeninas benedictinas y cistercienses (1200-1450)

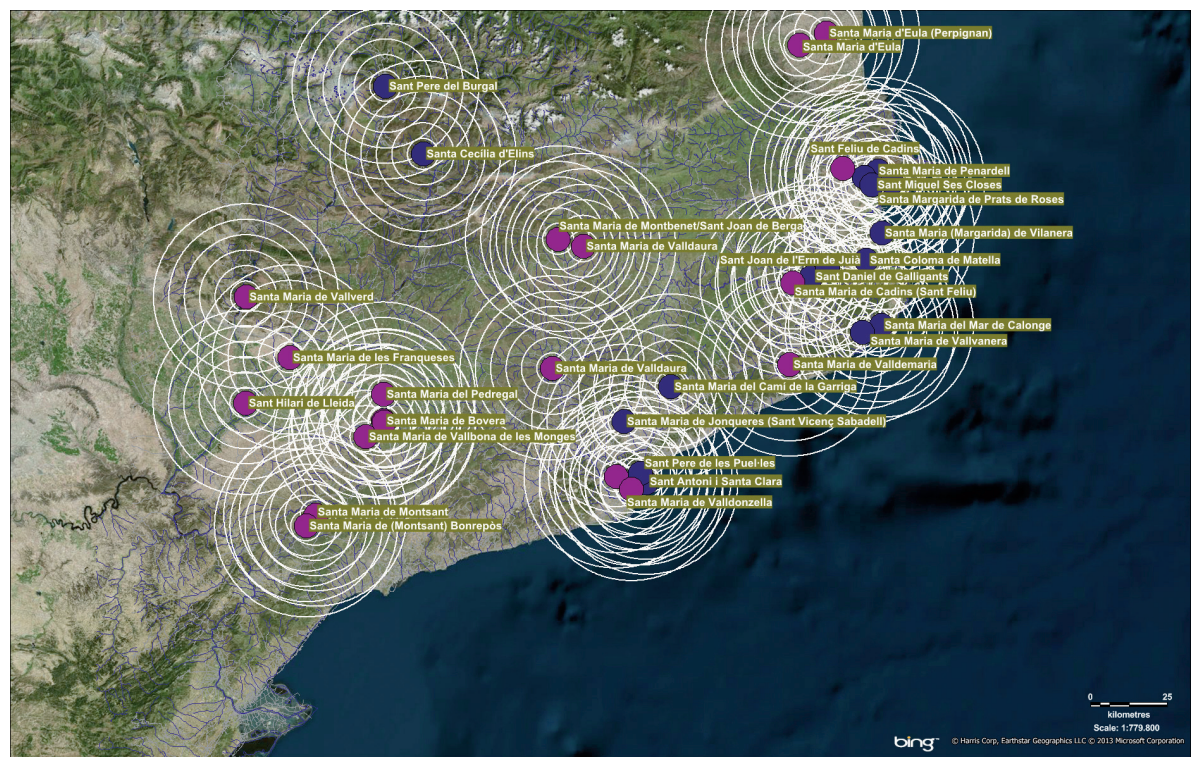

Comunidad femenina benedictina

Comunidad femenina cisterciense

En el tercero de los mapas se presentan comparativamente las fundaciones de benedictinas y cistercienses entre 1200 y 1450 . En este caso, se calculan además las áreas de influencia en círculos concéntricos de cinco kilómetros sucesivamente hasta un total de treinta kilómetros, entendiendo esta distancia como la máxima a recorrer en un día. Somos conscientes del carácter 
teórico de este mapa, que dada la fase inicial de nuestro estudio no incorpora todavía un análisis topográfico de las distancias entre monasterios, pero constituye una primera aproximación a las redes monásticas que desarrollaremos a lo largo de nuestra investigación.

La implantación de ambas ordenes que aquí se visualiza lleva de entrada a dos tipos de reflexión: por un lado, se constata la implantación mayoritaria de los monasterios benedictinos en la Cataluña Vella, totalmente ausentes en cambio en tierras de la Cataluña Nova, mientras que, en contrapartida, sorprende la diversidad de implantación de los monasterios cistercienses femeninos, mayoritarios en la Cataluña Nova, pero presentes también y de forma significativa en la Cataluña Vella, (donde no encontramos en cambio comunidades masculinas, salvo el priorato de Santa Maria de Jonqueres, dependiente de Vallbona, y el priorato de Valldaura, establecido en 1460 al disolverse la comunidad femenina). Por otro lado, la importancia cuantitativa de fundaciones cistercienses femeninas en comparación a otros territorios y a las propias fundaciones masculinas en Cataluña aparece como un fenómeno evidente y que, sin embargo, está poco explicado, pasando incluso con frecuencia inadvertido por la investigación relacionada con los monasterios en la historia de Cataluña ${ }^{47}$. Finalmente, el establecimiento de las áreas de influencia de estos monasterios nos permite abrir una puerta a la reflexión sobre las redes monásticas medievales. Descubrimos así que la mayor parte de monasterios se distribuyen a través del territorio en distancias inferiores a un día de viaje, lo que nos permite establecer fuertes vínculos de comunicación entre ellos. Así lo vemos, por ejemplo, entre los centros de benedictinas situados en torno a las ciudades de Girona y Barcelona que, dejando aparte los algo más alejados centros pirenaicos de Burgal y Elins, dibujan un arco de comunicación casi completo a través del territorio de la Cataluña Vella. Lo mismo ocurre con los monasterios cistercienses, que en su expansión por la Cataluña Nova se sitúan siempre a menos de un día de camino de uno o varios de los monasterios de su congregación. Esto nos permite interpretar ya no sólo la existencia de una red de relaciones intensa entre centros, sino también formular un modelo de distribución en el que las distancias entre monasterios (a excepción de las comunidades pirenaicas) no superan el recorrido máximo de una jornada de viaje hasta el monasterio más cercano de su congregación.

\footnotetext{
${ }^{47}$ Frente a los cuatro monasterios masculinos (Poblet, Santes Creus, Escarp y Lavaix, este último ligado a Bonnefont) de los que dependían dos prioratos también masculinos, encontramos trece monasterios femeninos dispersos por toda la geografía de Cataluña, de los que dependían dos prioratos femeninos y dos masculinos.
} 


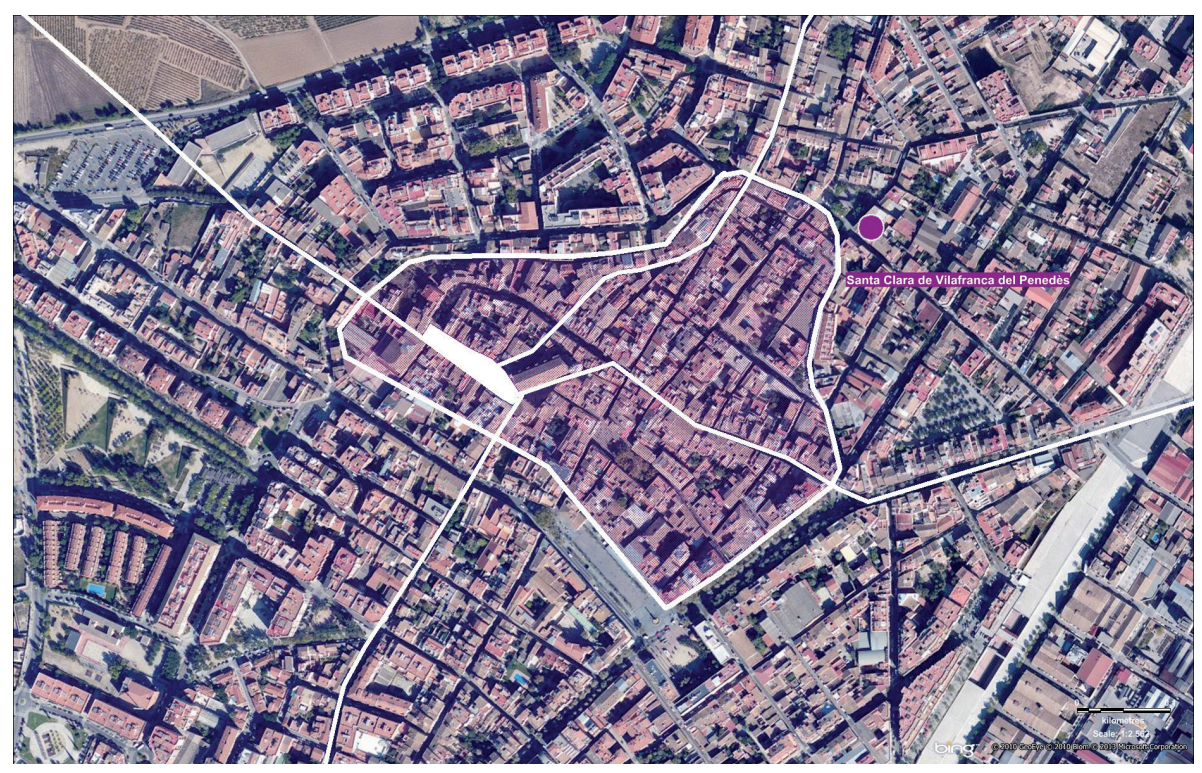

Fig. 4. Santa Clara de Vilafranca del Penedès

En este último mapa se muestra una de las posibilidades más atractivas del análisis del "paisaje" de un monasterio, poniéndolo en relación con la red de caminos, las murallas, los mercados, los recursos hidráulicos, etc. El estudio integrado de fuentes documentales, arqueológicas y territoriales nos permite conocer con bastante precisión las formas urbanas de los núcleos de población medievales y la relación que se establece entre ellos y los centros monásticos que se fundaron en su interior. Así lo vemos en el caso de Vilafranca del Penedès, que tras la formidable expansión vivida durante los siglos XIII y XIV se convirtió en el centro económico, político y social del territorio del Penedés. Este proceso de expansión culminó a mediados del siglo XIV con la construcción de una consistente muralla ${ }^{48}$. Es en este contexto de ampliación urbana cuando documentamos la fundación del monasterio de Santa Clara del Penedès realizada por Blanca de Nápoles, mujer de Jaime II. Esta fundación constituye un testimonio más de la importancia del núcleo urbano de Vilafranca del Penedès a principios de la Baja Edad Media. El mapa representa algunos de los datos históricos conocidos sobre este entorno urbano: el trazado de la muralla, las principales vías de comunicación que cruzaban su trama urbana

${ }^{48}$ A. Àlvarez et al., Traçat i morfologia, pp. 309-317. 
y la comunicaban con el resto del territorio, así como la plaza de mercado semanal y feria anual que articulaban su vida económica. También aparece el monasterio de Santa Clara de Vilafranca del Penedès, cuyo emplazamiento llegamos a discernir a pesar de la poca información de que disponemos ${ }^{49}$ : más allá de la muralla, cerca de la puerta de Santa Clara, en el espacio de confluencia entre la actual plaza Milà i Fontanals y la calle de Pines. El impacto del monasterio en la toponimia urbana de la ciudad ha quedado fosilizado en la denominación de la calle de Santa Clara, una de las principales vías de acceso al monasterio medieval. La representación de todos estos elementos en una misma cartografía nos ayuda a precisar la ubicación de los centros monásticos y a analizarlos no como espacios aislados en sí mismos sino como ámbitos de relación con el núcleo urbano que les rodea, permitiéndonos profundizar en los vínculos que se establecen entre ellos y la vida económica y social de la ciudad. Ulteriores estudios deberían aspirar, en este caso o en aquellos casos donde sea posible, a ampliar la investigación hacia el diseño del área de influencia y de las posesiones y patrimonio del monasterio y su integración en el paisaje de conjunto.

Finalmente es posible hacer una valoración de las informaciones que nos aportan los cuatro mapas en su conjunto. Ya sólo con esta somera mirada a través de cuatro ventanas al paisaje monástico femenino de la Edad Media catalana se dibujan algunos caminos de reflexión importantes y se suscitan algunos interrogantes de interés: sorprende por un lado la poca implantación monástica en el Pirineo, exceptuando la zona más oriental del pirineo ampurdanés. Este hecho además se acentúa con el tiempo pues son sobre todo benedictinas las que aparecen tempranamente en zonas pirenaicas, estando prácticamente ausentes en cambio órdenes más modernas como las mendicantes. Los mapas destacan la concentración de comunidades alrededor de los centros urbanos, sobre todo pero no sólo de los más relevantes como Girona o Barcelona, y avalan así la tesis de una urbanización de la espiritualidad protagonizada en buena medida por mujeres. Interesante parece la secuencia fundacional a lo largo de los ríos de la cuenca del Ebro: Segre (desde Puigcerdà), Pallaresa (desde Sant Pere del Burgal) y hasta el mismo Ebro pasando por Elins, Vallverd, Balaguer, Lleida y Tortosa. Esta ruta es desde antiguo la más utilizada en las comunicaciones. Prácticamente el resto de los monasterios están abocados a las orillas de ríos que desembocan directamente en el Mediterráneo. Queda clara la

\footnotetext{
${ }^{49}$ La ubicación del monasterio de Santa Clara de Vilafranca del Penedès nos es desconocida. A pesar de ello, gracias a la ayuda de Josep Bosch, medievalista especializado en el estudio evolutivo de la Vilafranca medieval, y mediante varias menciones documentales indirectas, hemos podido establecer su situación concreta. Sirvan estas líneas de agradecimiento a su desinteresada colaboración.
} 
existencia de una red de monasterios establecida en base a razones políticas y económicas específicas, pero también en función de una lógica territorial que el uso de los Sistemas de Información Geográfica nos debe permitir dilucidar con más detalle. Desde este marco es posible emprender el estudio de los factores de diferenciación en la dinámica de implantación de los monasterios masculinos y femeninos así como establecer los parámetros de la dinámica patrimonial de posesiones y dominios monásticos. Por estos caminos discurrirán en el futuro algunas de nuestras investigaciones que pretenden potenciar este tipo de análisis en el conjunto de los reinos peninsulares.

\section{BIBLIOGRAFÍA CITADA}

Adell, Joan-Albert, Arquitectura alt-medieval a Cataluña. Una definició del tipus monàstic canonical del segles IX al XI, Barcelona, Escola Tècnica Superior de Barcelona, 1991, (tesis doctoral inédita).

Àlvarez, Bruna; Esteve, Xavier; Senabre, Maria Rosa; Soler, Maria, Traçat i morfologia de la muralla medieval de Vilafranca del Penedès, en II Congrés d'Arqueologia Medieval i Moderna a Cataluña: Els conjunts monàstics, Barcelona, ACRAM, 2003, pp. 309-317.

Arízaga, Beatriz, La recuperación del paisaje urbano medieval: Propuesta metodológica, en Bonachía, Juan Antonio (coord.), La ciudad medieval, Valladolid, Universidad de Valladolid, 1996, pp.13-34.

Benvenuti Papi, Anna, "In castro poenitentiae". Santità e società femminile nell'Italia medievale, Roma, Herder, 1990.

Benvenuti Papi, Anna; Carpini, Claudio; Degl'Innocenti, Emiliano; Tromboni, Lorenza, Topografia sacra della Toscana, Florencia, Galluzzo SISMEL, 2000.

Berger, Jean-François; Bertoncello, Frédérique; Braemer, Frank; Davtian, Gourguen; Gazenbeek, Michiel (dirs.), Temps et espaces de l'homme en société, analyses et modèles spatiaux en archéologie, "XXVes Rencontres internationales d'archéologie et d'histoire d'Antibes", Antibes, Éditions APDCA, 2005.

Bertrand, Georges, L'Archéologie du paysage dans la perspective de l'écologie historique, "Caesarodunum" 13 (1978), pp. 132-138.

Bloch, Marc, Les caractères originaux de l'Histoire rurale française, Oslo, Institut pour l'étude comparative des civilisations, 1931.

Bloch, Marc, La société féodale, París, Albin Michel, 1939-1940.

Bodenhamer, David. J.; Corrigan, Jonh; Harris, Trevor M. (eds.), The Spatial Humanities: GIS and the Future of Humanities Scolarship, Indiana, University Press, 2010. 
Bolòs, Jordi, Els orígens medievals del paisatge català. L'arqueologia del paisatge com a font per a conèixer la història de Cataluña, Barcelona, Publicacions de l'Abadia de Montserrat, 2004.

Bolòs, Jordi, Monestir de Sant Llorenç prop Bagà. Les fonts documentals. Els primers temps del monestir (segles IX-XIII), en Investigacions arqueològiques $i$ històriques al Bergadà. Sant Llorenç prop Bagà. Sant Quirze de Pedret, Barcelona, Diputació de Barcelona, 1995, pp. 11-12. (Quaderns científics i tècnics de restauració monumental; 6).

Bolòs, Jordi; Busqueta, Joan J. (eds.), Territori i Societat a l'Edat Mitjana: Historia, Arqueologia, Documentació, vols. I-V, Lérida, Universitat de Lleida, 1997-2010.

Bolós, María de, Cuestiones de terminología, en Conferencias del I Congreso de Arqueología del Paisaje, 1990, Barcelona, Universidad de Barcelona, 1992.

Bond, James, Monastic Landscapes, Stroud, Tempus, 2004.

Bradford, John, Ancient Landscape. Studies in Field Archaeology, Londres, G. Bell and sons, 1957.

Busquets, Cesc; Pastor, Isidre, Una transformació de l'espai urbà a la Barcelona de finals del segle XVI. La construcció del convent de carmelites descalces, en II Congrés d'Arqueologia Medieval i Moderna a Cataluña: Els conjunts monàstics, Barcelona, ACRAM, 2003, pp. 147-153.

Caballero Zoreda, Luis; Arce, Fernando; Utrero, M. Ángeles, Santa Comba de Bande (Orense). Arquitectura y documentación escrita, "Arqueología de la Arquitectura" 2 (2003), pp. 69-73.

Caballero Zoreda, Luis: El conjunto monástico de Santa María de Melque (Toledo). Siglos VIII-IX. (Criterios utilizados para diferenciar restos arqueológicos de monasterios tardoantiguos), en García de Cortázar, José Ángel; Teja, Ramón (coords.), Monjes y monasterios hispanos en la Alta Edad Media, Aguilar de Campoo, Centro de Estudios del Románico, 2006, pp. 99-146.

Cabré i Pairet, Montserrat: "Deodicatae y Deovotae". La regulación de la religiosidad femenina en los condados catalanes, siglos IX-XI, en Muñoz, Ángela (coord.), Las mujeres en el cristianismo medieval. Imágenes teóricas y cauces de actuación religiosa, Madrid, Asociación Cultural Al-Mudayna, 1989, pp. 169-182.

Caby, C., et al., Espaces monastiques et espaces urbains de l'Antiquité tardive à la fin du Moyen Âge, "Mélanges de l'École française de Rome, Moyen Âge" 124/1 (2012).

Cantarell, Elena; Comas, Mireia, Espais de religiositat femenina a Barcelona de finals del segle XIV, en II Congrés d'Arqueologia Medieval 
i Moderna a Cataluña: Els conjunts monàstics, Barcelona, ACRAM, 2003, pp. 133-139.

Chouquer, Gérard, Cours d'Archéomorphologie, Carto-interprétation, Photointerprétation, 3 vols., Besançon, Association pour la Promotion de l'Archéologie des Paysages, 1990.

Chouquer, Gérard, Quels scénarios pour l'histoire du paysage? Orientations de recherche pour l'archéogéographie, Coímbra - Oporto, Centro de Estudos Arqueologicos das Universidades de Coimbra e Porto, 2007.

Chouquer, Gérard, Traité d'archéogéographie. La crise des récits géohistoriques, París, Errance, 2008.

Chouquer, Gérard, L'analyse de morphologie urbaine. L'exemple de Beja (Portugal), vol. II., Coímbra, 2012.http://www.formesdufoncier.org/ index.php?rub=thematiques/espurbains.

Clarke, David L. (ed.), Spatial Archaeology, Cambridge, Academic Press, 1977.

Collar, Anna, Network Theory and Religious Innovation, "Mediterranean Historical Review" 22/1 (2007), pp. 149-162.

Collins, Tracy, The Other Monasticism: Killone Nunnery, Co.Clare,(Heritage Archeology Ireland Guide), Dublín, Archaeoloy Ireland, 2007.

Criado-Boado, Felipe, Del terreno al espacio: planteamientos y perspectivas para la arqueología del paisaje, Santiago de Compostela, Laboratorio de Arqueoloxia e Formas Culturais, 1999.

Erickson, Bonnie H., Social Networks and History: A Review Essay, "Historical Methods: A Journal of Quantitative and Interdisciplinary History" 30 (1997), pp. 149-157.

Fortacín Piedrafita, Javier, La donación del diácono Vicente al monasterio de Asán y su posterior testamento como obispo de Huesca en el siglo VI. Precisiones críticas para la fijación del texto, "Cuadernos de Historia Jerónimo Zurita" 47-48 (1983), pp. 7-70.

García de Cortazar, José Ángel; Teja, Ramón (coords.), Monjes y monasterios hispanos en la Alta Edad Media, Aguilar de Campoo, Centro de Estudios del Románico, 2006.

Garí, Blanca, The Sacred Space of Meditation. Nunneries and Devotional Performance in the Territories of the Crown of Aragon (14th-15th centuries), "The Journal of Medieval Monastic Studies" 3 (en prensa).

Garí, Blanca; Nieto-Isabel, Delfi-Isabel, Topografía de la asistencia: mujeres y hospitales en la Barcelona medieval como hipótesis metodológica, ponencia inédita presentada en el congreso Els Abrils de l'Hospital 2013. Fonts documentals i gràfiques per a l'estudi històric dels hospitals, Barcelona, 2013. 
Graña Cid, María del Mar, Religiosas y ciudades. La espiritualidad femenina en la construcción sociopolítica urbana bajomedieval (Córdoba, siglos XIII-XVI), Córdoba, Asociación Hispánica de Estudios Franciscanos, 2010.

Guermandi, Maria Pia, La Sfida della complessità " "Archeologia e Calcolatori” 22 (2011), pp. 441-445.

Guix, Juan Carlos; Soler, Maria; Martín, Marc; Fosalba, Montserrat; Mauri, Alfred, Introducción y colonización de plantas alóctonas en un área mediterránea: evidencias históricas y análisis cuantitativo, "Orsis" 16 (2001), pp. 125-165.

Hodder, Ian; Orton, Clve, Spatial Analysis in Archaeology, Cambridge, University Press, 1976.

Jornet Benito, Núria, El monestir de Sant Antoni de Barcelona: l'origen i l'assentament del primer monestir de clarisses a Cataluña, Barcelona, Publicacions de l'Abadia de Montserrat, 2007 (Scripta et documenta; 76).

Kelly, Anne; Hillier, Amy (eds.), Placing History: How Maps, Spatial Data, and GIS Are Changing Historical Scholarschip, Redlands, ESRI Press, 2008.

Lilley, Keith D., Mapping the medieval city: plan analysis and urban history, "Urban History" 27 (2000), pp. 5-30.

López Mullor, Albert; Caixal, Àlvar; Vila, Josep Maria, El monestir de Sant Llorenç prop Bagà (Guardiola de Bergadà). Assaig d'evolució histórica, en II Congrés d'Arqueologia Medieval i Moderna a Cataluña: Els conjunts monàstics, Barcelona, ACRAM, 2003, pp. 35-48.

Mauri, Alfred; Soler, Maria, Les conques baixes del Llobregat i l'Anoia a la fi del 1er. mil·leni, en Gerbert d'Orlhac i el seu temps: Cataluña i Europa a la fi del ler mil·leni, Vic, Eumo Editorial, 1999, pp. 209-225.

Mauri, Alfred; Soler, Maria; Vives, M., Paisatge i mercat a l'antiga baronia de Castellvell de Rosanes en XLIII Assemblea intercomarcal d'estudiosos. Martorell, 4 i 5, novembre, 2000 (en prensa).

Mauri, Alfred; Soler, Maria, Els castells i l'organització i l'explotació del territori a la línia del Llobregat i al Penedès (segles IX-XI), en Els castells a la Mediterrània nord occidental, Arbúcies, Museu Etnològic del Montseny, 2003, pp. 131-140.

Mauri, Alfred; Carulla, Narcís, La casa de Deodades de Castellbisbal, en II Congrés d'Arqueologia Medieval i Moderna a Cataluña: Els conjunts monàstics, Barcelona, ACRAM, 2003, pp. 129-132.

Mauri, Alfred, La configuració del paisatge medieval: el comtat de Barcelona fins el segle XI, Barcelona, Universitat de Barcelona, 2006 (tesis doctoral). 
Nieto-Isabel, Delfi-Isabel, "Qui spiritus ambo sunt unum": The Network of Beguin Spirituality in 14th-century Languedoc, en Garí, Blanca (ed.), Women's Networks of Spiritual Promotion in the Peninsular Kingdoms, Roma, Viella, 2013, pp. 147-166.

Orejas, Almudena, Arqueología del paisaje: historia, problemas y perspectivas, “Archivo Español de Arqueología” 64 (1991), pp. 191-230.

Orengo, Héctor, Arqueología de un paisaje cultural pirenaico de alta montaña. Dinámicas de ocupación del valle del Madriu-Perafita-Claror (Andorra), Tarragona, ICAC, 2010 (tesis doctoral).

Palet, Josep Maria, Estudi territorial del Pla de Barcelona. Estructuració $i$ evolució del territori entre l'època iberoromana i l'altmedieval. Segles II-I a.C. - X-XI d.C., Barcelona, Centre d'Arqueologia de la Ciutat - Institut de Cultura - Ajuntament de Barcelona, 1994.

Palet, Josep Maria; Ejarque, Ana; Miras, Yannick; Riera, Santiago; Euba, Itxaso; Orengo, Héctor, Formes d'ocupació d'alta muntanya a la vall de la Vansa (Serra del Cadí-Alt Urgell) i a la vall del Madriu-PerafitaClaror (Andorra) estudi diacrònic de paisatges cuturals pirinencs, "Tribuna d'Arqueologia" (2006), pp. 229-253.

Palet, Josep Maria; Ejarque, Ana; Miras, Yannick; Orengo, Héctor, Formas de paisaje de montaña y ocupación del territorio en los Pirineos orientales en época romana: estudios pluridisciplinares en el valle del Madriu-Perafita-Claror (Andorra) y en la Sierra del Cadí (Cataluña). Proceedings of the XVII International Congress of Classical Archaeology, "Bollettino di Archeologia" (2011), pp. 67-79.

Preiser-Kapeller, Johannes, (Not so) Distant Mirrors: a complex macro-comparison of polities and political, economic and religious systems in the crisis of the 14th century, en Proceedings of the International Conference The Angevin Dynasty (14th Century), Targoviste (Rumania), Octubre 21-23 2011 (en prensa).

Riu-Barrera, Eduard, L'arqueologia dels monestirs en els darrers temps. Aportacions i problemes, en II Congrés d'Arqueologia Medieval $i$ Moderna a Cataluña: Els conjunts monàstics, Barcelona, ACRAM, 2003, pp. 185-192.

Ruiz, Albert, Notes històriques de la parròquia de Castellbisbal, Castellbisbal, Parròquia de Sant Vicenç de Castellbisbal, 1998.

Sancho, Marta, Els Altimiris, en Sénac, Philippe (ed.), Histoire et Archéologie des Sociétés de la Vallée de l'Èbre (VIIe - XIe siècles), Toulouse, CNRS, 2010, pp. 67-90.

Soler, Maria, Estructura econòmica i model de poblament. Morfogènesi evolutiva dels nuclis d'hàbitat concentrat al comtat de Barcelona entre 
els segles X $i$ XIII. 2 vols., Barcelona, Universitat de Barcelona, 2002 (trabajo de DEA inédito).

Soler, Maria, Feudalisme i nucleació poblacional. Processos de concentración de l'hàbitat al comtat de Barcelona entre els segles X $i$ XI, "Acta historica et archaeologica mediaevalia" 23-24 (2002), pp. 69-101.

Soler, Maria, Els espais d'intercanvi. El mercat en el procés de gènesi i consolidació del feudalisme al comtat de Barcelona (segles IX a XIII), Barcelona, Universitat de Barcelona, 2006 (tesis doctoral).

Fecha de recepción del artículo: noviembre 2013

Fecha de aceptación y versión final: abril 2014 